\title{
La Corte Constitucional y los casos difíciles en el iusprivatismo: creacionismo judicial o descubrimiento de derechos implícitos ${ }^{1}$
}

Manuel Antonio Coral Pabón ${ }^{2}$

\section{INTRODUCCIÓN}

El presente trabajo pretende abordar colombiana. La seguridad jurídica contractual algunos efectos prácticos derivados de la frente al descubrimiento de derechos implícitos», constitucionalización del derecho privado, en en el cual se pretende determinar cómo se afecta particular, de los litigios contractuales entre la seguridad jurídica de los contratantes cuando, particulares, revisados en sede de tutela por la al aplicar derechos y obligaciones implícitas en Corte Constitucional colombiana. Se trata de principios constitucionales a la solución de casos un artículo concebido dentro del proyecto de relacionados con litigios contractuales privados, investigación denominado «El derecho judicial de la Corte Constitucional sustituye, mediante las obligaciones en la jurisprudencia constitucional subreglas, disposiciones vigentes de rango legal.

1 Artículo concebido en el marco del proyecto de investigación que adelanta el autor en el Doctorado en Derecho de la Universidad Santo Tomás «El Derecho Judicial de las obligaciones en la Jurisprudencia Constitucional Colombiana. Un análisis desde la teoría estándar de la argumentación jurídica».

2 Estudiante de Doctorado en Derecho V Cohorte, Universidad Santo Tomás. Correo electrónico: manuelantoniocoral@gmail.com 
Este problema se justifica en la necesidad de estudiar la forma en que la recepción de la teoría de los derechos implícitos en la jurisprudencia constitucional ha permitido el nacimiento de obligaciones no consensuadas, en el sentido tradicional del término, erigiéndose la jurisprudencia en fuente autónoma de las mismas. La utilidad de la investigación radica en que permitirá replantear tesis vigentes sobre autonomía privada y seguridad jurídica en el marco de la constitucionalización del derecho privado. De otro lado, su importancia se evidencia en que una sistematización del derecho judicial de las obligaciones, analizado a la luz de las concepciones material y pragmática de la argumentación, permitirá determinar si se encuentra o no justificada la sustitución de normas legales por principios constitucionales y cuáles son los límites de la misma en un estado social de derecho.

Para este propósito se adopta el método histórico hermenéutico. La investigación histórica busca «reconstruir el pasado de la manera más objetiva y exacta posible, para lo cual de manera sistemática recolecta, evalúa, verifica y sintetiza evidencias que permitan obtener conclusiones válidas, a menudo, derivadas de hipótesis» (Guerra, 2009, p. 79) y se fundamenta en la revisión de fuentes legales, jurisprudenciales y doctrinarias.

Así pues, en el presente artículo, a partir del método inductivo, se analiza una sentencia en particular, proveniente de nuestro Alto Tribunal, en procura de arribar a conclusiones generales relacionadas con algunos debates abordados hoy en día por la teoría jurídica y la filosofía del derecho, atinentes al creacionismo y discrecionalidad judiciales y, principalmente, a la teoría de los derechos implícitos, los cuales han encontrado tierra fértil en el modelo del Estado Constitucional.

Si bien la argumentación mediante ejemplo que ahora se plantea invita a correr el riesgo de incurrirse en la falacia de la generalización, el fallo escogido como pilar de este estudio refleja una tendencia de la cual hace parte nuestra Corte y que ha contribuido a ahondar las graves dificultades de distinción existentes hoy en día entre los problemas jurídico-fácticos y los político-filosóficos, derivados de la constitucionalización del derecho privado (Calderón, 2011).

\section{EFECTOS DE LA CONSTITUCIONALIZACIÓN DE LOS LITIGIOS CONTRACTUALES. EL CASO DE LA SENTENCIA T-769 DE 2005}

El caso que sirve de pretexto para estas reflexiones, y que por vía de revisión de acción de tutela correspondió su estudio a la Corte Constitucional, cuenta con los siguientes elementos fácticos relevantes:

Un grupo de personas celebraron un contrato de arrendamiento de locales comerciales con una sociedad mercantil que se encontraba en estado de liquidación, propietaria de un edificio donde funcionaba un centro comercial. 
Durante la ejecución del contrato de arrendamiento sobrevino un incendio de grandes proporciones, cuyas causas no fueron atribuidas a un agente concreto que hubiere permitido la imputación de algún tipo de responsabilidad civil. Una vez reconstruido el edificio, los antiguos arrendatarios invocaron a su favor el reconocimiento del derecho de preferencia al que se refiere el artículo 521 del Código de Comercio, a fin de que se les permitiere ocupar nuevamente los locales ya reconstruidos, eximiéndoseles del deber de pagar primas o valores especiales. Este requerimiento no fue atendido por la sociedad arrendadora, quien por el contrario exigió el pago de unos cánones incrementados en porcentajes que a juicio de los otrora arrendatarios bordeaban entre el 100 y el 150 por ciento.

Frente a la negativa de la sociedad propietaria del edificio de acceder a las pretensiones de sus antiguos contratantes, algunos de estos optaron por acudir a la justicia en ejercicio de sendas acciones de tutela que fueron negadas en las instancias respectivas, las cuales, a la postre, fueron seleccionadas por la Corte Constitucional para su revisión, generándose en consecuencia la Sentencia T-769 de 2005, con ponencia de la magistrada Clara Inés Vargas Hernández.

La Corte, en contravía de lo decidido por los falladores iniciales, aceptó las súplicas de los accionantes, ordenando, en consecuencia, que se asignen a los actores los locales reconstruidos en las mismas condiciones contractuales iniciales. La Alta Corporación fundamentó su decisión en el desconocimiento, por parte de la antigua arrendadora, de derechos fundamentales, tales como el trabajo, mínimo vital y debido proceso, todo ello como una consecuencia directa de aplicar al caso el principio constitucional de solidaridad.

La forma en que la Corte Constitucional abordó el estudio de este caso y construyó su ratio decidendi genera una serie de preguntas como: (i) ¿la Corte encontró un caso difícil y para ello debió acudir para su solución a principios constitucionales? (ii) ¿ La Corte realizó un trabajo de interpretación, descubriendo, incluso, derechos y obligaciones implícitas? o, por el contrario, ¿incurrió en el terreno del creacionismo judicial? y (iii) ¿La Corte excedió los límites de la discrecionalidad judicial, propios del modelo de Estado Social de Derecho?

\section{LOS CASOS DIFÍCILES EN EL IUSPRIVATISMO. ACERCA DE UN NUEVO TIPO DE CASO DIFÍCIL}

En este orden de ideas, el caso sub examine se califica de entrada como perteneciente a aquellos denominados "fáciles», si se considera que la problemática ínsita en el mismo encontraba una clara y predecible solución en reglas vigentes de los códigos Civil y de Comercio, reflejada en el siguiente razonamiento: 
- El contrato de arrendamiento de locales comerciales se regula por los artículos 518 y siguientes del Código de Comercio y dada la remisión normativa de que trata el artículo 822 ídem, lo no previsto en el estatuto mercantil se sujetará a lo ordenado por el Código Civil en lo pertinente.

- La conflagración que implicó a los locales arrendados generó la destrucción de la cosa arrendada, causal de terminación de los contratos de arrendamiento a que alude el artículo 2008, numeral $1^{\circ}$ del Código Civil.

- Un contrato expirado por causas legales pierde su poder generador de derechos y obligaciones para las partes.

- El reconocimiento del derecho de preferencia invocado por los accionantes no era de recibo por dos principales razones: (i) No se pueden invocar derechos derivados de contratos ya finiquitados por causas legales y (ii) surge el derecho de preferencia de los arrendatarios cuando el arrendador, mediante el desahucio respectivo, da por terminado el contrato de arrendamiento informando que el local será reparado, reconstruido o demolido, y una vez realizadas las obras necesarias, el antiguo arrendatario tiene prelación para ocupar nuevamente los inmuebles, sin que resulte obligado a pagar primas o valores especiales (art. 521, Código de Comercio). En el caso que analizóla Corte Constitucional no se evidencian los elementos fácticos que hubieren justificado la exigibilidad del derecho de preferencia.

¿Qué motivó entonces a nuestra Corte para «constitucionalizar» un caso claramente resuelto en disposiciones del derecho privado de rango legal, de las cuales se aparta sin apelar siquiera a la excepción de inconstitucionalidad? ¿Nos encontramos frente a un nuevo tipo de casos difíciles?

\section{Los casos difíciles}

Francisco Laporta nos presenta un concepto de caso difícil que sirve de punto de partida para la reflexión ulterior en torno a la actitud de nuestro Tribunal Constitucional:

El caso difícil sería aquel en el que la pregunta por el estatus normativo de una acción o por la calificación jurídica de una situación no encuentra en principio respuesta explícita en el derecho identificado mediante los criterios que nos suministra el sistema de fuentes. Entonces el juzgador ha de buscar esa respuesta en algún lugar. Si suponemos que esa respuesta no está en ninguno de los 
arsenales de pautas del derecho preestablecido, entonces el juez se ve forzado, por la obligación de fallar, a 'crear' derecho ex novo (Laporta, 2002, p.138).

En síntesis, un caso difícil presupone la inexistencia de regla previa alguna que aporte a la solución (Dworkin, citado en Laporta, 2002).

De lo anterior se infiere que el juez se halla frente a un caso difícil cuando la respuesta esperada no se puede ubicar en el sistema de fuentes para el caso colombiano, integrado por la ley, costumbre, jurisprudencia, doctrina y principios generales del derecho, según la concepción clásica.

Tratándose de asuntos relacionados con obligaciones en derecho privado (civiles y comerciales), la doctrina tradicional del derecho civil, auspiciada por la jurisprudencia del máximo tribunal de la justicia ordinaria, ha sostenido inveteradamente que la teoría de las fuentes de las obligaciones encuentra su sustento en el clasicismo del decimonónico Código Civil (cinco fuentes: ley, contrato, cuasicontrato, delito, cuasidelito), en el modernismo atribuido a Josserand (cuatro fuentes: ley, acto jurídico, hecho ilícito, enriquecimiento sin causa) o en otro tipo de teorías contemporáneas que, inclusive, han llegado a afirmar que la única y verdadera fuente de las obligaciones, por su carácter autónomo, es la ley (otros extienden este carácter también al contrato) (Valencia y Ortiz, 2004).

En lo que respecta en particular a la ley, esta se ha caracterizado tradicionalmente por constituir una fuente de obligaciones explícitas, si consideramos que el legislador de manera literal o descriptiva le ha indicado al obligado las cargas patrimoniales que debe asumir. El ideal del contrato también es ese, generar obligaciones claras, todo en aras de la seguridad jurídica. Esto se ha dado gracias a que la ley y el contrato, en su condición de fuentes obligacionales, se reitera, normalmente se encuentran bajo la estructura de reglas.

A partir del criterio anotado, la Corte Constitucional no se encontró avocada al análisis de un caso difícil. Todo lo contrario, el sistema de fuentes vigente en Colombia ofrecía a su disposición una serie de herramientas legales bajo la forma de reglas, cuya estructura de antecedente y consecuente permitía, bajo la técnica de la subsunción, formular una respuesta predecible: bajo el esquema normativo iusprivatista vigente, los accionantes carecían del derecho de reclamar el derecho de preferencia. Pero al parecer la Corte consideró que esta respuesta, propia del formalismo jurídico, no era la más adecuada, la mejor solución que el ordenamiento jurídico podría ofrecer a los tutelantes y en un acto de desprecio interpretativo cierra los códigos Civil y de Comercio y constitucionaliza el caso: la respuesta correcta la buscará en disposiciones con estructura de principios (normas abiertas, inacabadas, máximas de optimización) (Alexy, 2003).

En teoría, nos encontraríamos frente a un nuevo tipo de casos difíciles: aquellos que cuentan con una solución explícita en las reglas jurídicas, pero esta es desestimada al considerarse que no es la mejor ofrecida por el ordenamiento jurídico y, por ende, se 
apela a las normas con estructura de principios de rango constitucional, inaplicando normas vigentes, sin hacer uso de la excepción de inconstitucionalidad a que hace referencia el artículo $4^{\circ}$ constitucional.

La noción de caso difícil nos plantea un dilema: la solución de este tipo de asuntos judiciales refleja a un funcionario judicial adelantando una especial labor de búsqueda del derecho implícito inmerso en las normas generales o ubica al juez en el plano del creacionismo judicial (Laporta, 2002). No sobra advertir que algunos autores consideran que los derechos implícitos no se derivan de un acto de interpretación judicial sino de una «construcción normativa del juez constitucional» (Candia, 2014, p. 484).

\section{La teoría de los derechos implícitos}

Si un derecho subjetivo es el contenido de una norma, bajo esta lógica el derecho implícito será el contenido de una norma implícita, esto es, normas no expresas o «carentes de formulación en los textos normativos (dicho de otro modo, las normas que no pueden ser reconducidas a precisas disposiciones normativas en cuanto significados de éstas)»(Guastini, 2014, p. 493).

El punto a dilucidar consiste en determinar si el principio constitucional de solidaridad o derechos al trabajo, mínimo vital y debido proceso, citados en la sentencia, involucran, de manera implícita para los arrendatarios de locales comerciales, un derecho de preferencia sui generis, diferente al consagrado en el Código de Comercio.

Para arribar a una conclusión someteremos el razonamiento judicial contenido en la Sentencia T-769 de 2005 de nuestro Tribunal Constitucional a dos tipos de test que se construyen a partir de las tesis de dos autores, ya referenciados, que han trabajado la temática de los derechos implícitos: el italiano Riccardo Guastini y el español Francisco Laporta Sanmiguel.

Guastini(2014) plantea que los derechos implícitos pueden surgir de razonamientos precedidos de inferencias lógicamente válidas a partir de premisas normativas expresas, pero otros razonamientos, a juicio de este autor la gran mayoría, carecen de estas características: «no son inferencias lógicamente válidas (en la mayoría de los casos son entimemas) y/o representan premisas que no son normas expresas». Las normas derivadas de este último caso serían una «actividad nomopoiética de los intérpretes» (pp. 493-494).

A partir de la revisión jurisprudencial, que implicó diversos tribunales constitucionales, Guastini concluyó que los derechos implícitos surgen de dos tipos de ejercicios argumentativos: (i) inferir un derecho implícito de un derecho explícito en el cual está inmerso y (ii) inferir un derecho implícito de un principio expreso o igualmente implícito (2014, pp. 494-495). 
Un ejemplo del primer tipo de argumentación lo presenta la Corte Constitucional colombiana en la Sentencia T-627 de 2012. Haciendo referencia a los derechos reproductivos, consideró:

36.- Como se puede deducir de lo anterior, las prerrogativas que conceden los derechos reproductivos son parte de los derechos fundamentales reconocidos en la Constitución de 1991 pues especifican las facultades que se derivan necesariamente de su contenido en el ámbito de la reproducción. Por esta razón la Declaración de la Conferencia Internacional sobre Población y Desarrollo del Cairo de 1994 indicó que esta categoría de derechos "abarca ciertos derechos humanos que ya están reconocidos en las leyes nacionales, en los documentos internacionales sobre derechos humanos y en otros documentos pertinentes de Naciones Unidas aprobados por consenso" (principio 4). En este sentido, los derechos reproductivos están implícitos en los derechos fundamentales a la vida digna (artículos 1 y 11), a la igualdad (artículos 13 y 43), al libre desarrollo de la personalidad (artículo 16), a la información (artículo 20), a la salud (artículo 49) y a la educación (artículo 67), entre otros (Sentencia T-627 de 2012, M.P. Humberto Sierra Porto).

Otro ejemplo lo encontramos en el Tribunal Constitucional chileno, el cual ha reconocido el derecho a la identidad personal, entendido como el derecho a conocer los orígenes biológicos, al considerarse que se deriva del derecho a la igualdad en dignidad y derechos de las personas (art. $1^{\circ}$ inc. $1^{\circ}$ Constitución de Chile) y de la tesis de que los derechos esenciales de la persona, reconocidos por la Constitución y los tratados internacionales, se convierten en límites a la soberanía legislativa (Constitución de Chile, art. $5^{\circ}$, inc. $2^{\circ}$ ) (véase Candia, 2014).

El segundo tipo de argumentación se aprecia en la Sentencia T-426 de 1992, de nuestra Corte Constitucional. En esta oportunidad, el Tribunal dedujo la existencia del derecho al mínimo vital a partir de los principios de dignidad humana y Estado Social de Derecho (Sentencia T-426 de 1992, M.P. Eduardo Cifuentes Muñoz).

En el pronunciamiento contenido en la Sentencia T-769 de 2005, la Corte apeló a los dos ejercicios argumentativos ya relacionados: a contrario sensu lo dispuesto en los códigos Civil y de Comercio, infiere la existencia del derecho de preferencia de los arrendatarios (derecho implícito) de dos derechos explícitos (trabajo y debido proceso) y de un derecho igualmente implícito (mínimo vital). De otro lado, la Corte infiere el derecho de preferencia de los arrendatarios (derecho implícito) de un principio explícito (el de solidaridad).

Esta revisión inicial, de corte estrictamente formal, permitiría afirmar en gracia de discusión que la Corte no incurrió en el terreno del creacionismo judicial y simplemente, a través de una actividad de interpretación, «descubrió» el derecho de preferencia de los damnificados arrendatarios de locales comerciales en derechos y principios constitucionales, con presupuestos diferentes a los descritos en el artículo 521 del Código de Comercio. Esta prerrogativa, previamente calificada 
de sui géneris por derivarse directamente de la Carta, prevalecería sobre las reglas infraconstitucionales. Lo anterior, no obstante los errores argumentativos que abundan en la sentencia, los cuales merecen un acápite especial in fine.

Laporta (2002) nos plantea una serie de reglas que pueden ser encontradas en el derecho implícito, las cuales se analizarán en paralelo con los argumentos que sustentan la Sentencia T- 769 de 2005:

\begin{tabular}{|c|c|}
\hline $\begin{array}{l}\text { Tipos de reglas en el derecho implícito } \\
\text { (Laporta, 2002, pp. 140-146) }\end{array}$ & $\begin{array}{l}\text { ¿Se infieren en la Sentencia T-769 de } \\
\text { 2005? }\end{array}$ \\
\hline $\begin{array}{l}\text { 1.Reglas implicadas formalmente en } \\
\text { otras reglas explícitas. Son aquellas que } \\
\text { surgen por deducción, por ejemplo, los } \\
\text { argumentos a contrario. }\end{array}$ & $\begin{array}{l}\text { Este tipo de reglas no aparecen en la } \\
\text { sentencia. }\end{array}$ \\
\hline $\begin{array}{l}\text { 2. Reglas implicadas conceptualmente en } \\
\text { otras reglas. Se derivan de la multiplicidad } \\
\text { de significados que pueden tener los } \\
\text { términos, desde el punto de vista de su } \\
\text { significado natural u obvio o técnico. }\end{array}$ & $\begin{array}{l}\text { Este tipo de reglas no aparecen en la } \\
\text { sentencia. La Corte no se detiene en } \\
\text { analizar las posibles acepciones que pueden } \\
\text { tener conceptos como arrendamiento, } \\
\text { preferencia, etc. }\end{array}$ \\
\hline $\begin{array}{l}\text { 3. Reglas producto de enunciados } \\
\text { interpretativos. Por ejemplo, los conceptos } \\
\text { jurídicos indeterminados o las reglas } \\
\text { abiertas. Para Laporta, interpretar un } \\
\text { enunciado jurídico sería "pasar de su } \\
\text { formulación lingüística original a otra } \\
\text { formulación lingüística que pretende captar } \\
\text { y expresar mejor lo que la primera trata de } \\
\text { comunicarnos. O, dicho de otra manera, } \\
\text { 'interpretar' es sustituir una formulación de } \\
\text { la regla por otra» (p. 141). }\end{array}$ & $\begin{array}{l}\text { La sentencia se sustenta en desarrollos } \\
\text { prácticos de conceptos jurídicos } \\
\text { indeterminados o reglas abiertas. El fallo } \\
\text { surge de definir el sentido y alcance, para } \\
\text { el caso concreto, de normas contentivas } \\
\text { de principios (solidaridad) y derechos } \\
\text { fundamentales (trabajo, debido proceso, } \\
\text { etc.). }\end{array}$ \\
\hline $\begin{array}{l}\text { 4. Reglas que cumplen el propósito o } \\
\text { fin de otras normas explícitas. En todo } \\
\text { enunciado o norma puede existir un } \\
\text { propósito o fin, intención del legislador, a } \\
\text { partir de la cual el intérprete, apelando a la } \\
\text { teleología, puede inferir una norma nueva. } \\
\text { Para ello se requeriría que el propósito sea } \\
\text { conocido y, de otro lado, que la norma } \\
\text { resultante del trabajo interpretativo sea } \\
\text { necesaria y coherente con el resto del } \\
\text { ordenamiento jurídico. }\end{array}$ & $\begin{array}{l}\text { La Corte no apela a una interpretación } \\
\text { teleológica. El fallo no se sustenta en el } \\
\text { discernimiento de la finalidad perseguida } \\
\text { por el legislador o constituyente. }\end{array}$ \\
\hline
\end{tabular}




\begin{tabular}{|l|l|l|}
\hline 5. Reglas que se obtienen a partir de & El principio de solidaridad soporta \\
enunciados normativos de principios y & el argumento judicial. Se invoca \\
valores. Si se considera que los principios & explícitamente y sustenta la declarada \\
y valores son una especie de anhelo del & vulneración de derechos fundamentales \\
legislador, fuerza es concluir que deben ser & cuya titularidad radicaba en cabeza de \\
complementados con una regla precedida & los antiguos arrendatarios. El problema \\
de una justificación explicativa del porqué & detectado por Laporta se hace evidente \\
la regla creada se infiere del principio. & en esta sentencia: la regla deducida \\
Estas reglas ofrecen un problema: aquellas & del principio de solidaridad (deber de \\
derivadas de principios constitucionales & arrendarles preferentemente a los antiguos \\
podrían contrariar reglas previas definidas & arrendatarios) choca de frente con normas \\
por el legislador. El derecho implícito \\
resultaría entonces incompatible con el \\
derecho explícito.
\end{tabular}

A manera de conclusión inicial: el sustento teórico ofrecido por Guastini y Laporta, aplicado al análisis de la Sentencia T-769 de 2005, permitiría afirmar que, en el caso sub examine, la Corte Constitucional infirió derechos implícitos de normas de textura abierta explícita. No creó, por ende, derecho nuevo. Sin embargo, no se puede dejar de lado el inconveniente práctico expuesto por Laporta (2002):

Otro importante tema de discusión en relación con los llamados principios y valores es el de su utilización por el juzgador en relación con las reglas jurídicas establecidas. Como los principios y valores se encuentran muchas veces en la propia Constitución y las reglas aparecen en leyes ordinarias del poder legislativo, se ha podido considerar la idea de que argumentando sobre la base de un principio el juez obtenga una regla incompatible con otra regla prevista en una ley establecida y la aplique en detrimento de ésta. Así, el juez, vía principio, obtiene del derecho implícito una norma jurídica que opone a otra emanada del legislador. Este proceder se festeja a veces como expresión de la llamada justicia material y ha sido a veces utilizado por jueces criptopolitizados, en España y en otros países, para oponerse a una mayoría parlamentaria en nombre de la Constitución (p. 146).

Esta reflexión del autor ibérico da paso al siguiente punto relacionado con el margen de acción judicial en un modelo de Estado Social de Derecho. 


\section{ESTADO SOCIAL DE DERECHO Y DISCRECIONALIDAD JUDICIAL. ¿EL DERECHO IMPLÍCITO PUEDE SUBVERTIR EL DERECHO EXPLÍCITO?}

Si el derecho implícito se deriva de principios y derechos constitucionales, prevalecería sobre el derecho explícito de rango legal o infraconstitucional. Esta respuesta, demasiado simplista, fundamentada en elementales criterios de jerarquía normativa, tal vez no sea suficiente para solucionar la confrontación que en la práctica podría presentarse y efectivamente se presenta (la Sentencia T-769 de 2005 es un ejemplo de ello) entre el derecho implícito y disposiciones de derecho explícito.

Continuando la línea de este trabajo, el punto a dilucidar consiste en determinar si, so pretexto de la constitucionalización de un caso de derecho privado, al aplicar a la solución del mismo directamente principios o derechos fundamentales, las reglas derivadas de este ejercicio interpretativo pueden subvertir disposiciones previas, vigentes, de origen legislativo. En caso afirmativo, ¿cuáles serían los límites que el Estado Social de Derecho le confiere a esa «subversión»?

La constitucionalización de un caso de derecho privado sería procedente en tres situaciones distintas, a saber:

a. Cuando las normas de rango legal (por ejemplo, aquellas contenidas en los códigos Civil, de Comercio y disposiciones complementarias) no ofrecen una solución concreta y esta debe ser ubicada en normas de rango constitucional.

b. Cuando las normas de rango legal antes referidas ofrecen una solución concreta al caso, pero por contrariar preceptos constitucionales son inaplicadas en ejercicio de la excepción de inconstitucionalidad del artículo $4^{\circ}$ de la Carta Política. En este escenario, el fallador encuentra la solución en normas de rango superior (de carácter explícito o implícito).

c. Cuando las normas de rango legal ofrecen una solución que el juez considera no satisfactoria, por no ser la mejor que el sistema jurídico le puede ofrecer al caso, evento en el que, sin hacer uso de la excepción de inconstitucionalidad, el funcionario judicial se separa de esas reglas y encuentra la solución en disposiciones constitucionales. Es un nuevo tipo de caso difícil al que ya se hizo alusión.

El caso analizado en el decurso del presente trabajo se ubicaría en la última de las citadas alternativas. Sin que la Corte lo afirme expresamente en su fallo, parecería que la solución que ofrecían los códigos a un pleito relacionado con el aparente desconocimiento del derecho de preferencia de unos antiguos arrendatarios de 
locales comerciales no era la idónea o adecuada y, por ello, la misma resulta de la aplicación directa de preceptos constitucionales abstractos, indeterminados.

La adopción de principios constitucionales en la Carta Política de 1991, entre ellos el principio constitucional de solidaridad, adoptado por la Constitución en varias disposiciones, entre ellas los artículos $1^{\circ}$ y 95 , ha servido de fundamento para que la Corte Constitucional, en su papel de guardiana de la Constitución e intérprete del sentido y alcance de los principios y derechos fundamentales, genere una serie de precedentes en casos originados en relaciones de derecho privado, atinentes, entre otros, a: (i) la forma en que la solidaridad puede limitar el ejercicio de ciertas potestades (v.gr. autonomía de la voluntad contractual), convirtiéndose en fuente de derechos y obligaciones no consagradas expresa o literalmente en disposiciones normativas (civiles, comerciales o convencionales), que por vía de interpretación se han encontrado implícitas en dicho principio ${ }^{3}$, y (ii) la determinación de formas especiales de responsabilidad extracontractual que modifican los postulados legales, doctrinarios y jurisprudenciales vigentes en esta materia. ${ }^{4}$

De lo anterior se deduce que el caso base de estudio no es aislado, sino que hace parte de una tendencia jurisprudencial de nuestro Alto Tribunal, consistente en que, en casos en los cuales opera la constitucionalización de un litigio de derecho privado, el mismo puede ser solucionado a partir del descubrimiento de derechos implícitos insertos en la Carta Política, con prescindencia de normas vigentes insertadas en regímenes jurídicos, como el civil o comercial.

Este trabajo de buceo en las aguas del derecho explícito para encontrar derechos implícitos amerita tres llamados de atención formulados por Guastini (2014):

- Aceptar la posibilidad de que el juez escudriñe en la legislación en procura de derechos implícitos podría generar una inconveniente injerencia de los órganos jurisdiccionales en la actividad del legislativo, más aún si se considera que aquellos cuentan con deficiencias en legitimación democrática.

\footnotetext{
3 Sobre los efectos de la constitucionalización del derecho contractual y casos concretos de aplicación del principio de solidaridad en asuntos relacionados con contratos, puede consultarse: Cárdenas Mejía, Juan Pablo (2007). A manera de ejemplo, en la sentencia de la Corte Constitucional T-520 de 2003, M.P. Rodrigo Escobar Gil, al analizar un contrato de mutuo celebrado por una entidad financiera con una persona que se convirtió en víctima de un secuestro, la Corte impuso al mutuante, y en favor del mutuario, una serie de cargas obligacionales nuevas, no consagradas expresamente en la ley o contrato, derivadas de la interpretación, que para el caso muy particular el Alto Tribunal realizó del principio de solidaridad.
}

4 En la Sentencia SU-645 de 1997, M.P. Fabio Morón Díaz, la Corte Constitucional prácticamente desmontó los elementos de la responsabilidad civil extracontractual, atribuyendo responsabilidad civil a un ente hospitalario privado sin haberse demostrado, en un caso de transmisión de VIH, culpa y relación de causalidad con el daño causado. 
- Los derechos implícitos son heterogéneos: el juez puede descubrir «libertades, pretensiones, inmunidades y poderes» (Hohfeld, citado en Guastini, 2014, p. 496).

- Los derechos implícitos no necesariamente conllevan un vínculo jurídico entre Estado y ciudadano (efecto vertical):

[...] pueden también tener efectos «horizontales» en las relaciones inter-privados. En otras palabras, es posible que un «nuevo» derecho civil (en sentido amplio) tenga como efecto el nacimiento de una nueva obligación civil correspondiente. Lo que es discutible desde el punto de vista de una filosofía política liberal. Probablemente ningún liberal desaprobaría el enriquecimiento del patrimonio de derechos de los ciudadanos, pero no es en absoluto obvio que se haya de aprobar también el incremento de sus obligaciones, o sea, la restricción de su libertad (Guastini, 2014, p. 496).

El permanente descubrimiento de derechos implícitos, que sin lugar a dudas ha impactado las relaciones jurídicas iusprivatistas, hace parte del reconocido activismo judicial de la Corte Constitucional Colombiana, sin parangón en América Latina (con excepción tal vez de la Sala Constitucional de la Corte Suprema de Costa Rica) (Herdegen, 2006). Dicho activismo se sustenta en un cambio de discurso a partir de nuevas relaciones de poder, en el marco del modelo de Estado Social de Derecho.

\section{El cambio de discurso en el marco de nuevas relaciones de poder}

Lo expuesto invita a preguntarse: ¿En qué momento la ley perdió su rango de única fuente principal y obligatoria del derecho, y el derecho judicial, consignado en la jurisprudencia, adquirió el papel preponderante que actualmente ocupa en el sistema de fuentes? ¿En qué momento el juez colombiano abandonó su papel pasivo frente a la producción del derecho, un simple convidado de piedra, y se convirtió en un creador del mismo, hasta el punto de que hoy en día puede hablarse de un verdadero derecho judicial? Las respuestas se encuentran en el fenómeno de la constitucionalización del derecho, que se afianza a partir de la adopción del Estado Social de Derecho.

El denominado derecho continental siempre privilegió a la fuente ley por sobre las demás y esta influencia impuesta desde la conquista marcó las dinámicas de desenvolvimiento de las relaciones jurídicas hasta las postrimerías del siglo veinte. El legislador, que en su momento histórico reemplazó al monarca como titular del poder legislativo, se convirtió en un destinatario del poder de hacer las normas, las cuales debían ser interpretadas de manera fiel a su texto literal, so pena de violentar su espíritu. La rígida escuela de la exégesis y su principio de exclusividad de la ley en el sistema de fuentes (se consideraba que no existía más derecho que el codificado) 
(Blanco, 2010) marginaba a los jueces de cualquier tipo de protagonismo. En palabras de Laurent: «Los Códigos no dejan nada al arbitrio del intérprete; este no tiene ya por misión hacer el derecho, el derecho está hecho. No existe incertidumbre, pues el derecho está escrito en textos auténticos» (citado en Blanco, 2010, p. 58).

El discurso según el cual el juez carece de poder y de legitimidad para crear el derecho se mantuvo vigente históricamente para el caso colombiano e, inclusive, parecería que el mismo Constituyente de 1991 acogió la misma fórmula en el artículo 230 constitucional.

Sin embargo, la nueva Carta generó a su vez otras condiciones que permitieron el surgimiento de nuevas relaciones de poder que abonaron el terreno para un cambio de discurso, haciendo su entrada el protagonismo judicial, el cual ha permitido, incluso, que el referenciado artículo 230 hoy en día ya no signifique lo mismo que en tiempos de promulgación de la Carta, todo por efecto de la mutación constitucional a la que ha sido sometido, frente a lo cual ni el legislativo ni el ejecutivo han podido hacer nada al respecto ${ }^{5}$.

La revolución jurídica estuvo a cargo de la Corte Constitucional, quien de tiempo atrás viene considerando que en atención al derecho a la igualdad, el cual involucra la prerrogativa de recibir la misma protección y trato por parte de las autoridades públicas (art. 13 C.N.), los precedentes judiciales de altas cortes resultan obligatorios en casos con propiedades jurídicas similares. Por vía de interpretación, la Corte ha fijado el criterio (que incluso hoy en día aparece recogido en diversos textos de rango legal), de que en ciertas situaciones la jurisprudencia sí resulta obligatoria, controvirtiendo con ello la literalidad del artículo 230 ya referido. El texto de esta norma se mantiene intacto, como en sus orígenes, pero hoy su sentido es radicalmente diferente. Este es un paradigma de la mutación constitucional.

Para analizar la competencia que se ha atribuido la Corte Constitucional para introducir, por vía de interpretación, mutaciones normativas a preceptos de rango legal, e inclusive constitucional, resultan especialmente útiles las ideas expuestas por Roberto Bergalli (1994), autor que en el marco de la crisis del derecho positivo aborda

5 La particularidad de la mutación radica en el hecho de que, como resultado de una actividad interpretativa, se cambia el sentido o se da un alcance diferente a un precepto constitucional, sin alterar la literalidad del mismo. Un ejemplo clásico de este tipo de cambio constitucional, y posiblemente de los más conocidos, tiene que ver con el ya referenciado artículo 230 de la Carta. Al disponer que los jueces en sus decisiones «sólo están sometidos al imperio de la ley», relegando a la jurisprudencia, equidad, principios generales del derecho, y la doctrina al rango de «criterios auxiliares de la actividad judicial», lo que hizo el Constituyente de 1991 simplemente fue retomar el modelo tradicional imperante en Colombia, de inspiración romano germánica, basado en el predominio o reinado del derecho legislado. De la simple lectura de esta norma se infiere que la Asamblea Nacional Constituyente de ninguna manera pretendió generar una ruptura del modelo jurídico imperante hasta entonces, implantado desde las épocas de la conquista española. Todo lo contrario, mantuvo un statu quo. 
la denominada creatividad jurisprudencial (relacionada con la discrecionalidad jurisdiccional), figura en clara rebelión contra el formalismo, tema necesariamente relacionado con el debate positivismo vs. liberalismo jurídico.

La tesis tradicional según la cual los jueces no pueden crear derecho al carecer de legitimación democrática aparece atenuada en Bergalli cuando este sostiene que dicha legitimación aumenta cuando la sede jurisdiccional es entendida «como lugar de representación de sujetos e intereses de otro modo excluidos» (1994, p. 443). Ideas como esta amplían los límites del poder de creación del derecho por parte de los jueces, tema que podría abordarse para entender los efectos de la aplicación de principios constitucionales en el nuevo entendimiento de instituciones clásicas del derecho civil.

Lo expuesto anteriormente nos ubica en una realidad diversa que ha resultado difícil asimilar, sobre todo en ciertos sectores conservadores: nos encontramos frente a nuevas relaciones de poder que han generado un cambio del discurso tradicional; el derecho judicial está en capacidad de modificar, mediante ejercicios interpretativos, preceptos constitucionales y de rango legal. El derecho de los jueces ha puesto a temblar los cimientos de régimen de las obligaciones, contratos y la responsabilidad civil en derecho privado, el cual tradicionalmente le apostaba a la certeza.

Boaventura de Sousa Santos (2009), en un interesante estudio, explica cómo el poder judicial, tradicionalmente considerado como el poder más débil, comienza a ganar el ya referido "protagonismo» a partir de su "pérdida de la neutralidad política», el cual se afianza, entre otros factores, en la vinculación del derecho ordinario con la Constitución (p. 76 y ss.).

\section{La utilidad de la genealogía foucaultiana}

Nos encontramos entonces frente a nuevas prácticas judiciales que involucran otras formas de saber y discursos justificativos de verdad (Foucault, 1973).

$\mathrm{Al}$ analizar la competencia de la Corte Constitucional para plantear nuevas formas jurídicas en el marco de la teoría de las obligaciones, a partir de la constitucionalización de su régimen, valdría la pena apelar a la genealogía foucaultiana para rastrear el conocimiento, las prácticas a partir de los discursos en el marco de poder (dispositivo). Más aún, lo interesante en este caso en particular sería analizar el momento en el cual se generó el cambio de discurso y se nos presenta otra verdad auspiciada por nuevas relaciones de poder.

El trabajo de arqueología permitirá apreciar esas diferencias, las rupturas y continuidades. Explicará cómo transitamos del culto a la ley, concebido bajo los postulados de una muy arraigada exégesis pre-Constitución de 1991, al estado actual del nuevo derecho o derecho de los jueces. 
Dado que los análisis genealógicos «nos permiten desenmascarar los intereses que reposan detrás de las verdades» (Quinche y Quinche, 2006, p. 35), un estudio de este tipo generaría una aproximación a las justificaciones del discurso judicial que alteró o subvirtió el sistema tradicional de fuentes de las obligaciones, después de un reposicionamiento de la rama judicial con respecto a las otras ramas del poder. Esa aparente verdad absoluta que imperó en Colombia durante muchos años (reinado de la fuente ley en un derecho legislado y papel pasivo de jueces en la creación del derecho) se cuestiona desde la práctica judicial y resultaría interesante analizar la forma en que el derecho judicial «negó» la unicidad, objetividad, no revisabilidad, imparcialidad y universalidad de esa verdad que se nos impuso desde tiempos pretéritos ${ }^{6}$.

\section{¿El descubrimiento de derechos implícitos es una manifestación de la discrecionalidad judicial?}

Laporta (citado en Ruiz, 2010) se pregunta por qué en la actualidad los operadores judiciales se han vuelto tan proclives a la aplicación de normas con estructura de principios: será acaso por el replanteamiento del sistema de fuentes del derecho o

6 Los autores Quinche y Quinche sostienen que «Las teorías absolutas de la verdad suponen las siguientes características como elementos confortantes de lo verdadero. La verdad es única (solamente puede haber una caracterización completa y verdadera del mundo), es objetiva (no depende del hecho de presentarse a una conciencia), es no-revisable (lo que es verdadero no puede dejar de serlo y convertirse en falso), está fuera de las condiciones (la verdad es independiente de las condiciones del conocedor, de sus creencias, de sus órganos perceptores, de las condiciones del conocimiento, y de los procesos que llevan al conocer), es imparcial (no depende de los intereses, las necesidades, los afectos o las aversiones de cualquier persona o grupo), y es universal (si algo es verdadero no lo es solamente para mí, sino para cualquier otro). Esta teoría se encuentra íntimamente vinculada con una postura ontológica y epistemológica que le es correlativa: el mundo es un todo ordenado, cuya naturaleza depende de leyes rastreables y reconstruibles por parte de un sujeto conocedor, cuya constitución permite acceder a la verdad». Los autores en cita explican cómo a este tipo de teorías se opone Foucault mediante la negación de las características supra referidas, proponiendo una teoría perspectivista, cuyas condiciones serían «negación de la unicidad de la verdad (no hay una sola verdad para todos los ojos: hay tantas verdades cuantos puntos de vista haya sobre ella); negación de la objetividad (la forma como las cosas son solamente puede ser conocida a través de interpretaciones; diferentes sujetos harán diferentes interpretaciones que serán válidas para ellos, sin posibilidad de confrontarlas en sentido fuerte con otras versiones igualmente sustantivas pero contrarias); negación de la no-revisabilidad (de cualquier manera que el mundo sea interpretado, siempre habrá la posibilidad de suponer al menos una manera más adecuada de hacerlo, Nietzsche lo dice en Voluntad de poder, parágrafo 615: "entre un número mayor de criaturas, el conocimiento también adquirirá nuevas formas que aún no le son necesarias”); negación de la incondicionalidad (ninguna interpretación del mundo se presenta totalmente liberada de la naturaleza del sujeto que conoce, toda interpretación, por tanto, está condicionada, al menos en parte, por la naturaleza del sujeto que conoce); negación de la imparcialidad (toda interpretación del mundo sirve a los intereses de una cierta clase de sujeto)» (2006, pp. 34). 
por el auge del neoconstitucionalismo o por el ideal de búsqueda de justicia que a veces no se halla en las reglas o porque se trata de una tendencia contemporánea o, finalmente, porque se trata de un método complementario a ser utilizado en el quehacer judicial.

Cualquiera que sea la razón que se encuentre detrás de esta tendencia, lo cierto es que el Tribunal Constitucional colombiano, al solucionar conflictos de derecho privado, frecuentemente acude a las normas con estructura de principios, ubicando en los mismos derechos implícitos, en el ejercicio de una labor que necesariamente hace gala de discrecionalidad judicial, más aún si se considera que el juez se encontraría frente a la posibilidad de «descubrir», o para otros «crear», en palabras del ya citado Hohfeld, libertades, pretensiones, inmunidades y poderes (citado en Guastini, 2014, p. 496); posibilidad que no es absoluta, todo lo contrario, debe ser «[f]iscalizada para impedir que derive en arbitrariedad y que suponga una amenaza para los principios de igualdad y de seguridad jurídica» (Ruiz, 2010, p. 120).

Incluso, hablando de límites a la discrecionalidad judicial, Aragón Reyes (1997), al explicar el dilema del juez que transita entre la legalidad y la constitucionalidad, pone de presente el riesgo de "sobrevalorar la Constitución e infravalorar la ley», desconociendo la idea de que «[e]l principio de constitucionalidad debe ser entendido como un enriquecimiento, y no como una sustitución, del principio de legalidad» (Aragón, 1997, pp. 37 y 38). En el mismo sentido, Laporta señala, en lo atinente a la aplicación de derechos implícitos:

Mi posición al respecto es que el desarrollo de los principios y valores corresponde prioritariamente al poder legislativo, y que el derecho implícito inferido presuntamente de principios que se oponga al derecho establecido por el legislador no puede ser utilizado por el juzgador para resolver el caso (2007, p. 146).

La sentencia que ha servido de pretexto para estas reflexiones, es un buen ejemplo de sobrevaloración constitucional e infravaloración legal.

\section{ACERCA DE LOS YERROS DE LA SENTENCIA T- 769 DE 2005. BREVE ANÁLISIS A PARTIR DE LAS CONCEPCIONES DE LA ARGUMENTACIÓN DE ATIENZA}

El profesor español Manuel Atienza (2006) nos propone tres concepciones de la argumentación: formal, material y pragmática. 


\title{
a. Formal
}

Se relaciona con la coherencia externa o lógica del argumento. La Corte centra su tesis central en un argumento deductivo, en la modalidad de silogismo hipotético (Weston, 2007):

\author{
Si P entonces Q \\ Si Q entonces R \\ Por lo tanto, si P entonces $\mathrm{R}$
}

El análisis de la ratio decidendi de la sentencia, bajo esta fórmula, sería el siguiente:

Si de la aplicación del principio de solidaridad y reconocimiento de los derechos fundamentales al trabajo, mínimo vital y debido proceso, se infiere el derecho de preferencia de unos arrendatarios damnificados que se encuentran en estado de indefensión con respecto a sus arrendadores $(\mathrm{P})$ entonces el derecho de preferencia es un derecho implícito en otros principios y derechos fundamentales $(\mathrm{Q})$.

Si el derecho de preferencia es un derecho implícito en otros principios y derechos fundamentales $(\mathrm{Q})$ entonces, en caso de amenaza, desconocimiento o vulneración, debe ser protegido a través de la acción de tutela $(\mathrm{R})$.

Por lo tanto, si de la aplicación del principio de solidaridad y reconocimiento de los derechos fundamentales al trabajo, mínimo vital y debido proceso, se infiere el derecho de preferencia de unos arrendatarios damnificados que se encuentran en estado de indefensión con respecto a sus arrendadores $(\mathrm{P})$ entonces, en caso de amenaza, desconocimiento o vulneración del derecho de preferencia, debe ser protegido a través de la acción de tutela $(\mathrm{R})$.

En los argumentos deductivos, si las premisas son ciertas, indefectiblemente la conclusión también lo será. A contrario sensu, los defectos de las premisas comprometerán la sustentabilidad de la conclusión.

\section{b. Material}

En palabras de Atienza, la justificación de una decisión jurídica no solamente depende de aspectos formales o pragmáticos (efectos generados en los destinatarios de la argumentación), sino en que «efectivamente se ofrezcan razones de tipo apropiado» (Atienza, 2006, p. 183). Si bien la Corte realiza un esfuerzo interpretativo orientado a sustentar los derechos implícitos de lo que podría denominarse «los contratistas damnificados», el argumento adolece de yerros que le restan contundencia y comprometen la saturación del mismo: 
- La Corte confunde establecimiento de comercio y local comercial, siendo este último simplemente uno de los elementos integrantes del primero, al tenor de lo dispuesto en el artículo 516 del Código de Comercio. En unos apartes habla de arrendamientos de establecimientos de comercio y en otros alude a que los arrendatarios derivaban su sustento de la «administración de sus locales comerciales» (Sentencia T-769 de 2005, acápite $6^{\circ}$ ). Lo cierto es que el caso versó sobre el arrendamiento de unos locales comerciales sobre los cuales funcionaban establecimientos de comercio de propiedad de los arrendatarios.

- La Corte condiciona, sin razón alguna, la subsistencia de los arrendatarios comerciantes a volver a ocupar los mismos locales que utilizaban en el pasado, descartando de plano la posibilidad de que el ejercicio del comercio también podía realizarse en otras instalaciones. Se incurre en la falacia del olvido de alternativas (Weston, 2007).

- Se califican los actos de los arrendadores como ilegítimos, cuando estos actuaron amparados en normas legales vigentes que al prescribir la terminación de un contrato por la destrucción de la cosa arrendada los facultaba para disponer del bien. La violación de los derechos fundamentales de los antiguos arrendatarios solamente se determinó después de una sentencia de revisión de tutela, en la cual se reconocieron derechos implícitos.

- No obstante lo anterior, el principal error de la sentencia se advierte en los párrafos 11 y 12 del acápite $6^{\circ}$, en los cuales se reprocha a los arrendadores la omisión del deber de desahuciar a los arrendatarios ${ }^{7}$ :

7 Los eventos en los cuales se requiere el desahucio en arrendamiento de locales comerciales aparecen descritos en las siguientes normas (obsérvese que las causales son taxativas):

Art. 518. El empresario que a título de arrendamiento haya ocupado no menos de dos años consecutivos un inmueble con un mismo establecimiento de comercio, tendrá derecho a la renovación del contrato al vencimiento del mismo, salvo en los siguientes casos:

1. Cuando el arrendatario haya incumplido el contrato;

2. Cuando el propietario necesite los inmuebles para su propia habitación o para un establecimiento suyo destinado a una empresa sustancialmente distinta de la que tuviere el arrendatario, $y$

3. Cuando el inmueble deba ser reconstruido, o reparado con obras necesarias que no puedan ejecutarse sin la entrega o desocupación, o demolido por su estado de ruina o para la construcción de una obra nueva. 
Pues bien, de acuerdo a la posición ejercida por el arrendador, para evitar el abuso de sus derechos, ha debido aplicar de manera estricta las normas que sobre arrendamiento comercial se encuentran establecidas en la Ley. Esto hubiera permitido comunicar oportunamente la terminación del contrato y habría evitado que pese a no prestar el desahucio correspondiente se imposibilitara injustificadamente que los peticionarios hubieran proseguido con su labor en los locales respectivos. Dicha omisión, a saber, no aplicar los procedimientos previstos en la ley para notificar la terminación del contrato de arrendamiento, permiten aseverar a la Sala que el arrendador adoptó una postura ilegítima, vulnerando los derechos adquiridos y también el debido proceso como derecho fundamental indirecto.

El comportamiento que debió asumir el arrendador ante la inexistencia del correspondiente desahucio, en orden a garantizar los derechos fundamentales de los arrendatarios, era designar para cada uno de ellos un local comercial en el que siguieran desplegando su labor. Si existiera cualquier duda o controversia sobre la ejecución, prórroga o la renovación del contrato, aquel podría haber acudido a la jurisdicción ordinaria pero sin obstaculizar o impedir de manera alguna y hasta que ésta decidiera, que los comerciantes ejercieran sus labores libremente. Bajo esta óptica, es el arrendador que no profirió el desahucio correspondiente, quien tiene a su disposición los medios judiciales idóneos para plantear cualquier tipo de controversia sobre la ejecución del contrato. Poner a los arrendatarios damnificados a reclamar la entrega de sus locales por medios judiciales desconoce sus derechos fundamentales y desecha sin razón la expectativa legítima creada por la inexistencia del desahucio (Corte Constitucional, Sentencia T-769 de 2005).

Cabe preguntarse entonces si la destrucción de los locales que hacían parte del centro comercial obedeció a un incendio, ¿cómo esperaba la Corte Constitucional que los arrendadores hubieren desahuciado a sus arrendatarios con seis meses de antelación a la terminación del contrato, en estricto cumplimiento de lo ordenado por el artículo 520 del Código de Comercio?

\footnotetext{
Art. 520.- En los casos previstos en los ordinales 2o. y 3o. del artículo 518, el propietario desahuciara al arrendatario con no menos de seis meses de anticipación a la fecha de terminación del contrato, so pena de que éste se considere renovado o prorrogado en las mismas condiciones y por el mismo término del contrato inicial. Se exceptúan de lo dispuesto en este artículo los casos en que el inmueble sea ocupado o demolido por orden de autoridad competente.
} 


\section{c. Pragmática}

Finalmente, desde este punto de vista de la argumentación, analizada esta desde los destinatarios de la decisión judicial, la misma genera una percepción: la aplicación de derechos implícitos, desentrañados en disposiciones constitucionales, generó para la parte contra la cual se dirigió la acción de tutela no el deber de respeto a derechos preexistentes sino a deberes creados post facto (Guastini, citado en Arcos, 2002). Este punto indefectiblemente nos transporta al debate sobre la seguridad y certeza jurídicas, derivadas desde las épocas del reinado de la Escuela de la Exégesis y la Jurisprudencia de Conceptos, de la previsibilidad de las decisiones judiciales, aspecto que a partir de la Escuela del Derecho Libre se empieza a replantear cuando se acepta la idea de que la actividad del juez no es exclusivamente cognoscitiva, sino también valorativa (Arcos, 2002).

Sin lugar a dudas, estos deberes post facto pueden alterar la proporcionalidad de las cargas, característica civilista de los contratos bilaterales de naturaleza conmutativa, como el arrendamiento.

No sería extraño que alguien formule esta pregunta: ¿para qué los códigos si todos los casos pueden ser solucionados con la Constitución?

\section{CONCLUSIONES}

La discrecionalidad judicial, que hoy en día es una realidad en la práctica de los operadores judiciales, les ha permitido a estos descubrir, a través de ejercicios interpretativos y argumentativos, derechos implícitos derivados de normas con estructura de principios (abiertas, indeterminadas) tales como aquellas que consagran derechos fundamentales y principios propiamente dichos (las cuales pueden ser a su vez explícitas o implícitas). Este activismo judicial involucra un nuevo discurso, fruto a su vez de nuevas relaciones de poder generadas a partir del reposicionamiento de la rama judicial en el marco del Estado Social de Derecho.

Esta discrecionalidad, en manera alguna puede ser absoluta, cuenta con claros límites orientados, entre otros, a respetar la soberanía legislativa, a prescindir de la arbitrariedad y garantizar la igualdad y seguridad jurídicas que podrían verse comprometidas con este tipo de expresiones de derecho judicial.

Si bien aplicando las orientaciones que ofrece la doctrina foránea para determinar si los derechos implícitos son un acto de conocimiento o de valoración, que faculta la creación de nuevo derecho, en la práctica resulta muy difícil determinar lo uno o lo otro, por la sutileza que impregna este tipo de análisis. ¿El derecho de preferencia 
del arrendatario damnificado ostenta una naturaleza implícita o es nuevo derecho? Difícil determinarlo.

La aplicación de derechos implícitos en el marco de los litigios contractuales del derecho privado conlleva, a su vez, el discernimiento de obligaciones implícitas que posiblemente no fueron objeto de previsión contractual. Esta situación puede comprometer la estabilidad de las cargas obligacionales originarias, aspecto que sustentaría la socorrida afirmación de que este tipo de actividad judicial compromete la seguridad jurídica, que para cierto sector todavía se sustenta en la certeza y previsibilidad de las decisiones judiciales.

La Corte Constitucional, sin acudir a la excepción de inconstitucionalidad, ha inaplicado normas de rango legal a casos de derecho privado (que en principio se consideraban «fáciles») so pretexto de arribar a una solución a partir de la aplicación de normas implícitas halladas en disposiciones de rango superior. La posibilidad de que un derecho implícito de origen judicial controvierta disposiciones normativas vigentes de ascendencia legislativa repugna a cierto sector de la doctrina, bajo el entendido de que el principio de constitucionalidad no debe desplazar al de legalidad, sino complementarlo.

La adopción de derechos implícitos le exige al juez una fuerte carga argumentativa, desprovista de falacias y sofismas. 


\section{REFERENCIAS}

Alexy, R. (2003). Tres escritos sobre los derechos fundamentales y la teoría de los principios. Bogotá: Editorial Universidad Externado de Colombia.

Aragón Reyes, M. (1997). El juez ordinario entre legalidad y constitucionalidad. Bogotá: Editorial Universidad Externado de Colombia, Instituto de Estudios Constitucionales Carlos Restrepo Piedrahita.

Arcos Ramírez, F. (2002). La seguridad jurídica en la aplicación judicial del Derecho. De la previsibilidad a la argumentación, pp. 191-217. En Anuario de filosofía del derecho, 19, 191-217. Recuperado de: dialnet.unirioja.es/ descarga/articulo/756887.pdf

Atienza, M. (2006). El derecho como argumentación. Barcelona: Editorial Ariel.

Bergalli, R. (1994). Protagonismo judicial y representatividad política. En Revista Doxa , (15-16), 423 - 445. .

Blanco Zúñiga, G. (2010). De la interpretación legal a la interpretación constitucional. Bogotá: Editorial Ibañez.

Candia Falcón, G. (2014). Analizando la tesis de los derechos implícitos: comentario a la sentencia del Tribunal Constitucional recaída sobre el requerimiento de inaplicabilidad rol No. 2.408-2013 de 6 de marzo de 2014. En Revista de Derecho Universidad Católica del Norte, 21(1), 497-521. Recuperado de: http://www.scielo.cl/pdf/rducn/v21n1/art17.pdf

Cárdenas Mejía, J. P. (2007). Los derechos fundamentales y el derecho privado contractual. La situación en el derecho colombiano. En AA.VV. Constitucionalización del derecho privado, pp. 479-490. Bogotá: Eds. Universidades Externado de Colombia y Universidad del Rosario.

Calderón Villegas, J. J. (2011). La constitucionalización del derecho privado. La verdadera historia del impacto constitucional en Colombia. Bogotá: Editorial Universidad de los Andes.

Foucault, M. (1973). La verdad y las formas jurídicas. Recuperado de: www.catedras. fsoc.uba.ar/mari/Archivos/HTML/Foucault_verdad_formas_juridicas_ comp.htm [fecha de consulta: 5 de julio de 2015].

Guastini, R. (2014). Otras distinciones. Bogotá: Ed. Universidad Externado de Colombia. Guerra García, Y. M. (2009). Formación en investigación. Bogotá: Ed. Ciencia y Derecho. 
Herdegen, M. (2006). La Corte Constitucional en la relojería del Estado de Derecho. En AA.VV. Justicia Constitucional. El rol de la Corte Constitucional en el Estado contemporáneo, pp. 65-80. Bogotá: Editorial Legis.

Laporta San Miguel, F. (2002). La creación judicial y el concepto de derecho implícito. En Revista Jurídica Universidad Autónoma de Madrid, (6), 133-151. Recuperado de: https://repositorio.uam.es/bitstream/ handle/10486/3092/14239_6RJ132.pdf?sequence=1

Quinche Ramírez, V. A. y Quinche Ramírez, M. F. (2006). Foucault y el análisis genealógico del derecho. En Revista Estudios Socio Jurídicos, 8(2).

Ruiz, R.(2010). Sobre la discrecionalidad judicial en un Estado Constitucional. En: Cuadernos Electrónicos de Filosofía del Derecho, (20). Recuperado de: https://ojs.uv.es/index.php/CEFD/article/view/193

Santos, B. de S. (2009). Sociología jurídica crítica. Para un nuevo sentido común en el derecho. Bogotá: ILSA.

Valencia Zea, A. y Ortiz Monsalve, Á.(2004). Derecho Civil. De las obligaciones. Bogotá: Ed. Temis.

Weston, A. (2007). Las claves de la argumentación. Barcelona: Ed. Ariel.

\section{Jurisprudenciales}

Corte Constitucional. (1992). Sentencia T-426 de 1992, M.P. Eduardo Cifuentes Muñoz. Bogotá: Autor.

. (1997). Sentencia SU-645 de 1997, M.P. Fabio Morón Díaz. Bogotá: Autor. . (2003). Sentencia T- 520 de 2003, M.P. Rodrigo Escobar Gil. Bogotá: Autor. . (2005). Sentencia T- 769 de 2005, M.P. Clara Inés Vargas. Bogotá: Autor. . (2012). Sentencia T- 627 de 2012, M.P. Humberto Sierra Porto. Bogotá: Autor.

\section{Normativas}

Constitución Política de Colombia

Constitución Política de Chile

Código Civil colombiano

Código de Comercio colombiano 
Esta obra se editó en Ediciones USTA, Departamento

Editorial de la Universidad Santo Tomás. Se usó papel esmaltado de 300 gramos para la carátula y papel bond beige de 70 gramos para páginas internas. Tipografía: Minion Pro. Impreso por Xpress. 
a Dirección del Doctorado en Derecho se complace en presentar algunos trabajos de investigación realizados por estudiantes de este programa, los cuales constituyen una evidencia de los avances que cada uno de ellos ha logrado en cuanto a la estructura lógica del pensamiento científico e investigativo, así como de las técnicas propias de las diferentes metodologías empleadas.

Además del trabajo propio de la tesis doctoral, los estudiantes del Doctorado en Derecho deben presentar disertaciones o artículos que den cuenta de su capacidad investigativa, desde la formulación del problema de investigación hasta la pertinente y exhaustiva bibliografía.

La disciplinariedad de cada uno de los textos obedece a la misma razón de ser del Doctorado, ya que en él convergen diferentes campos del derecho a fin de que el estudiante desarrolle temas de interés para la comunidad académica e investigativa en el ámbito nacional e internacional. 